\title{
MANAJEMEN HUMAS: MEMBANGUN PERAN MASYARAKAT PADA LEMBAGA PENDIDIKAN
}

\author{
${ }^{1}$ Fajri Dwiyama, ${ }^{2}$ Adriani, ${ }^{3}$ Ismia, ${ }^{4}$ Riska Oktafiana \\ ${ }^{1}$ Fakultas Tarbiyah Institut Agama Islam Negeri Bone \\ fajridwiyama@iain-bone.ac.id \\ ${ }^{2}$ Fakultas Tarbiyah Institut Agama Islam Negeri Bone \\ Adrianiandrii99@gmail.com \\ ${ }^{3}$ Fakultas Tarbiyah Institut Agama Islam Negeri Bone \\ miahusjed@gmail.com \\ ${ }^{4}$ Fakultas Tarbiyah Institut Agama Islam Negeri Bone \\ Riskaoktafiana16@gmail.com
}

\begin{abstract}
The community is one of the main keys in developing educational institutions. High public participation in educational institutions, it is not impossible to deliver educational institutions to become quality institutions, still exist in the midst of competition between educational institutions, and become the most favorite institution in the community. This can be achieved if all stakeholders in educational institutions also exist in advancing the institution, in relation to the community. PR has a very big war in realizing this, but the facts show that most educational institutions have PR but have not been able to get people to participate in advancing education. This study aims to find out how much the role of stakeholders in educational institutions in building public relations, especially in Madrasah Aliyah Negeri 1 Bone, and further to find out what participation is given by the community for the advancement of these educational institutions. The method used in this research is a qualitative case study. The results obtained showed that Madrasah Aliyah Negeri 1 Watampone, which implemented good public relations management, was able to make the community participate in advancing education at the institution.
\end{abstract}

Keywords: Management, Public Relations, Society

\section{PENDAHULUAN}

Pengelolaan lembaga pendidikan di Indonesia telah menjadi perhatian masyarakat sejak dulu hingga sekarang. Dalam perjalanannya banyak lembaga pendidikan mengalami pasang surut dalam perkembangannya, terutama hubungannya dengan besaran partisipasi masyarakat dalam lembaga pendidikan tersebut. Besarnya partisipasi masyarakat dalam mendorong perkembangan lembaga pendidikan, menjadi tolak ukur keberhasilan pengelolaan lembaga. Namun tidak semudah membalikkan telapak tangan untuk membuat masyarakat berpartisipasi dalam pengembangan lembaga pendidikan, tidak semua mampu melakukannya. Keberhasilan dalam membangun partisipasi masyarakat pada lembaga pendidikan berkaitan erat dengan manajemen humas yang dimiliki.

Masyarakat dalam hubungannya dengan lembaga pendidikan memiliki beberapa peran tertentu. Ditegaskan dalam UU nomor 20 tahun 2013 pada bab XV pasal 54 dinyatakan bahwa: pertama, Peran serta masyarakat dalam pendidikan meliputi peran serta perseorangan, kelompok, keluarga, organisasi 
profesi dan organisasi kemasyarakatan dalam penyelenggaraan dan pelayanan pengendalian mutu pelayanan pendidikan. Kedua, Masyarakat turut ikut serta menjadi sumber pelaksana dan pengguna hasil pendidikan. Ketiga, Ketentuan tentang keikut sertaan masyarakat tertera dalam ayat 1 dan 2 yang diatur di dalam peraturan pemerintah. ${ }^{1}$ Jadi nyatanya pemerintah telah mengatur dengan baik, hubungan masyarakat dengan lembaga pendidikan dengan tujuan utama agar masyarakat turut serta berpartisipasi dalam meningkatkan kualitas serta kuantitas pendidikan. Namun lagi-lagi yang harus berperan aktif agar masyarakat dapat turut serta dalam pendidikan adalah lembaga pendidikan itu sendiri atau yang lebih spesifik yakni humas lembaga pendidikan.

Humas lembaga pendidikan memegang fungsi yang sangat vital dalam membangun partisipasi masyarakat. Dibutuhkan manajemen humas sehingga sesuatu yang direncanakan, hubungannya dengan masyarakat dapat terlaksana dengan baik. Beberapa tugas manajemen humas pada lembaga pendidikan yaitu 1) menjadi sumber informasi bagi masayarakat; 2) Membantu pemimpin yang karena tugastugasnya tidak dapat langsung memberikan informasi kepada masyarakat atau pihak-pihak yang memerlukannya; 3) Membantu pemimpin mempersiapkan bahan-bahan tentang permasalahan dan informasi yang akan disampaikan atau yang menarik perhatian masyarakat pada saat tertentu; 4) Melaporkan tentang pikiran-pikiran yang berkembang dalam masyarakat tentang masalah pendidikan; 5) Membantu kepala sekolah bagaimana usaha untuk memperoleh bantuan dan kerja sama; 6) Menyusun rencana bagaimana cara-cara memperoleh bantuan untuk kemajuan pelaksanaan pendidikan. ${ }^{2}$

Madrasah merupakan salah satu lembaga pendidikan yang mengambil peran di masyarakat sebagai agen pencerdas kehidupan bangsa. Namun dalam perjalanannnya pasang surut partisipasi masyarakat pada madrasah masih terus terjadi. Secara umum pandangan masyarakat terhadap lembaga pendidikan Islam telah mengalami dinamika. Jika dulu lembaga pendidikan Islam diasumsikan dengan lembaga kampungan, kurang bermutu, dan hanya diminati oleh masyarakat pedesaan dan kelas menengah ke bawah. Namun dalam perkembangannya pandangan tersebut sudah semakin ditinggalkan. ${ }^{3}$ Kendati sebagian madrasah telah memiliki tempat di hati masyarakat, namun sebagian lainnya masih mengalami kesulitan. Selain masalah dikotomi yang dialami oleh madrasah, persoalan lain bagi pendidikan madrasah adalah kontinuitas jenjang pendidikan madrasah bagi siswanya. Misalnya, siswa

\footnotetext{
${ }^{1}$ Qoimah Qoimah, "MEMBANGUN PELAYANAN PUBLIK YANG PRIMA: STRATEGI MANAJEMEN HUMAS DALAM PENYAMPAIAN PROGRAM UNGGULAN DI LEMBAGA PENDIDIKAN," Islamic Management: Jurnal Manajemen Pendidikan Islam (2018).

${ }^{2}$ Mulyono Mulyono, "TEKNIK MANAJEMEN HUMAS DALAM PENGEMBANGAN LEMBAGA PENDIDIKAN ISLAM,” ULUMUNA (2011).

${ }^{3}$ Nurul Ahsin, "PANDANGAN MASYARAKAT PERKOTAAN DALAM MEMILIH LEMBAGA PENDIDIKAN ISLAM: Studi Tentang Parental Choice in Education Di SD Plus Rahmat Kota Kediri," Didaktika Religia 3, no. 1 (2015), https://jurnal.iainkediri.ac.id/index.php/didaktika/article/view/153.
} 
yang lulus Madrasah Ibtidaiyah (MI), tidak melanjutkan ke Madrasah Tsanawiyah (MTs), hal ini disebabkan karena tingkat kepercayaan masyarakat masih belum maksimal dan akses yang belum maksimal, baik akses informasi maupun akses penggunaan. ${ }^{4}$

Telah banyak penelitian tentang pentingnya manajemen humas pada lembaga pendidikan. Hasil penelitian Murni menyatakan bahwa dewasa ini pembahasan mengenai humas dalam lembaga pendidikan masih belum difungsikan secara baik oleh lembaga pendidikan terutama dalam lembaga pendidikan Islam, padahal fungsi humas untuk lembaga pendidikan sangatlah penting. Karena dengan adanya humas yang baik, lembaga pendidikan dapat melanjutkan eksistensi lembaganya supaya bisa menggunakannya sebagai salah satu cara yang efektif untuk membuat lembaganya menjadi "ada" dan mempunyai pandangan yang baik di masyarakat. ${ }^{5}$ Peneliti lainnya yakni Nadlir dalam penelitiannya menyimpulkan bahwa peran humas yang merupakan komunikator madrasah ini berdampak pula pada peningkatan mutu pendidikannya. Baik berkaitan dengan kegiatan yang berhubungan dengan kualitas peserta didik, kuantitas peserta didik, pemenuhan sarana prasarana, keberlangsungan madrasah dan kegiatan lainnya. ${ }^{6}$

Begitu banyak masalah yang dihadapi Madrasah dalam membangun partisipasi masyarakat dalam lembaga pendidikan. Madrasah di kota-kota besar telah mengalami perkembangan yang begitu pesat disebabkan pemanfaatan akses teknologi serta berbagai infrastruktur dan sumber daya manusia yang mendukung eksistensi lembaga untuk menarik minat masyarakat. Namun bagaimana dengan di kota-kota kecil di pelosok wilayah Indonesia? Hal inilah yang menarik bagi penulis untuk meneliti lebih lanjut. Pemilihan Madrasah Aliyah Negeri 1 Bone sebagai lokasi penelitian karena lembaga tersebut telah menerapkan manajemen humas yang baik, juga letak geografisnya yang masuk sebagai kota kecil dimana teknologi, infrastruktur dan sumber daya manusia masih terbatas dalam melaksanakan manajemen humas. Selain itu, image tentang keberadaan madrasah sebagai lembaga pendidikan pilihan kedua setelah sekolah umum masih tertanam di benak masyarakat.

\footnotetext{
${ }^{4}$ M Maskur, "Eksistensi Dan Esensi Pendidikan Madrasah Di Indonesia," Terampil : Jurnal Pendidikan dan Pembelajaran Dasar (2017).

${ }^{5}$ Murni, “KONSEP MANAJEMEN HUMAS PADA LEMBAGA PENDIDIKAN ISLAM,” Jurnal Intelektualita (2017).

6 Nadlir, "MANAJEMEN HUBUNGAN MASYARAKAT DALAM PENINGKATAN MUTU PENDIDIKAN DI MADRASAH TSANAWIYAH (MTs.) MA'ARIF NU 1 JATILAWANG BANYUMAS" (INSTITUT AGAMA ISLAM NEGERI PURWOKERTO, 2018).
} 


\section{PEMBAHASAN}

\section{Manajemen Humas di Madrasah Aliyah Negeri 1 Bone}

Manajemen humas di Madrasah Aliyah Negeri 1 Bone diimplementasikan melalui proses perencanaan, pengorganisasian, pelaksanaan kerja, dan evaluasi. Kegiatan-kegiatan tersebut dilaksanakan sesuai dengan manajemen sekolah yang diterapkan di Madrasah Aliyah Negeri 1 Bone. Hal tersebut dilaksanakan sebagai upaya untuk menjamin dan menjaga mutu pekerjaan khususnya pada bagian hubungan sekolah dengan masyarakat.

\section{a. Perencanaan}

Proses perencanaan dilaksanakan di setiap awal tahun ajaran baru yang dilaksanakan oleh Kepala Madrasah beserta jajarannya. Hal ini diungkapkan oleh Bapak Abbas selaku Kepala Madrasah Aliyah Negeri 1 Bone, sebagai berikut:

Pada dasarnya manajemen humas telah dilaksanakan di madrasah karena ada wakamat humas, wakamat kesiswaan, wakamat sarana prasarana, dan wakamat kurikulum yang semuanya melakukan perencanaan. Biasanya setiap menghadapi tahun ajaran baru, sudah dilakukan perencanaan kegiatan humas yang akan dilaksanakan, dalam raker dimana saat raker tersebut semua wakamat memaparkan programnya.

Hal senada juga diungkapkan oleh Agussalim Wakil Kepala Madrasah bagian Humas:

Tahapan perencanaan dilaksanakan setiap awal tahunnya, bagian humas bertugas menyusun program kerja yang berkaitan dengan hubungan masyarakat. Program kerja yang diusung oleh Wakamad Humas adalah 1) hubungan sekolah dengan sekolah; 2) hubungan sekolah dengan tokoh masyarakat; 3) hubungan sekolah dengan pemerintah.

Sementara hasil observasi yang dilakukan oleh peneliti menunjukkan bahwa apa yang telah di paparkan oleh para narasumber di atas memang benar adanya. Ditemukan dokumen-dokumen yang menunjukkan bahwa telah dilaksanakannya proses perencanaan yang berkaitan dengan masalah kehumasan. Dokumen-dokumen yang dimaksud berupa berita acara rapat, daftar hadir, dan foto-foto kegiatan raker.

Efni Wati mengungkapkan bahwa perencanaan merupakan modal awal dari sebuah rangkaian kegiatan yang akan dilakukan. Keberhasilan sebuah kegiatan bergantung seberapa baik rencana yang disusun untuk mencapai tujuan yang diinginkan. Perencaan merupakan langkah awal untuk membangun hubungan baik dengan masyarakat dengan merencanakan program-program apa yang bisa dilakukan agar masyarakat bisa berpartisipasi pada lembaga pendidikan. ${ }^{7}$ Betapa pentingnya sebuah perencanaan sebagai langkah awal dalam menentukan keberhasilan sebuah program yang diharapkan.

\section{b. Pengorganisasian}

${ }^{7}$ Efni Wati, “Manajemen Hubungan Sekolah Dan Masyarakat,” Jurnal Manajer Pendidikan (2015). 
Pengorganisasian memiliki peranan tersendiri dalam proses manajemen yang bertujuan memudahkan pelaksanaan pekerjaan. Pada proses ini, dilakukan pembagian tugas sesuai dengan fungsi dan jabatan masing-masing. Proses pengorganisasian secara nyata tergambar pada struktur organisasi. Manda mengungkapkan bahwa pengorganisasian dibuat agar terjadi pembagian pekerjaan yang dapat dilaksanakan dengan penuh tanggung jawab. Adanya pengorganisasian memungkinkan setiap anggota yang ditempatkan, masing-masing memiliki profesionalitas kerja yang unggul, serta memudahkan dalam peningkatan kualitas baik kualitas individu maupun kualitas pekerjaan. Pengorganisasian menjadi sangat penting sebab jika pekerjaan dilaksanakan serampangan, tidak sesuai dengan keahlian seseorang maka kegagalan akan menunggu di akhir pekerjaan. ${ }^{8}$

Observasi yang dilakukan di Madrasah Aliyah Negeri 1 Bone nampak bahwa sekolah tersebut memiliki struktur organisasi humas. Bagian humas pada struktur terdiri atas wakamad humas, komite dan BK yang masing-masing memiliki tugas dalam menjalankan manajemen humas. Kepala Madrasah mengatakan bahwa:

Dalam struktur organisasi humas di Madrasah Aliyah Negeri 1 Bone, wakamad humas mempunyai turunan, dan turunannya itu adalah Komite Sekolah dan Bagian Bimbingan Konseling. Komite Sekolah bertugas membantu bagian humas di luar sekolah, sementara bagian Bimbingan Konseling membantu Humas di lingkungan internal sekolah.

Selanjutnya Kepala Madrasah menambahkan:

Selain Komite dan BK, bagian humas juga dibantu oleh wali kelas, karena wali kelas termasuk kedalam wilayah humas. Wali kelas merupakan orang tua siswa di sekolah dan wali kelas harus kuat hubungannya dengan orang tua siswa. Misalnya ada kebutuhan Humas terhadap orang tua siswa, biasanya hal itu dikomunikasikan ke orang tua siswa melalui wali kelas.

Hasil penelusuran dokumen-dokumen mengenai kompetensi orang-orang yang ditempatkan pada posisi humas, menunjukkan bahwa kriteria mereka sudah sesuai dengan yang diharapkan. Kepala Madrasah memilih orang-orang yang memiliki latar belakang pendidikan serta pengalaman menangani humas dengan baik.

\section{c. Pelaksanaan Kerja}

Program-program humas yang telah disusun pada perencanaan tidak dapat dicapai tanpa melalui proses pelaksanaan kerja. Dalam proses ini, pimpinan baik Kepala Madrasah maupun Wakamad Humas memiliki peran yang penting dalam mendorong serta memaksimalkan unsur-unsur yang berkaitan dengan pelaksanaan program kerja humas. Pelaksanaan program kerja humas di Madrasah Aliyah Negeri 1 Bone melibatkan semua komponen masyarakat, seperti masyarakat internal yaitu Kepala

\footnotetext{
${ }^{8}$ Manda, "FUNGSI PENGORGANISASIAN DAN EVALUASI PESERTA DIDIK," Kelola: Journal of Islamic Education Management 1, no. 1 (2016): 89-101.
} 
Madrasah beserta jajarannya, guru, tenaga kependidikan, dan siswa. Selain masyarakat internal mereka juga melibatkan masyarakat eksternal seperti orang tua siswa, tokoh masyarakat, instansi pemerintahan, dan instansi swasta. Beberapa kegiatan humas yang dilaksanakan di Madrasah Aliyah Negeri 1 Bone seperti gebyar bahasa jerman, maulid, kemah blok, porseni, bazar, buka puasa bersama, bagi-bagi takjil untuk masyarakat kurang mampu dan penggalangan dana kemanusiaan semuanya melibatkan mayarakat melalui partispasi bantuan dana. Selain kegiatan-kegiatan tersebut, humas Madrasah Aliyah Negeri 1 Bone memprioritaskan keterbukaan manajamen pendidikan kepada masyarakat. Keterbukaan yang dimaksud seperti pemanggilan orang tua beserta tokoh masyarakat jika ada hal-hal penting yang dirumuskan, misalnya perumusan visi misi madrasah, perencanaan program pengembangan madrasah, pembuatan tata tertib, serta konsultasi mengenai perkembangan peserta didik selama mengikuti masa studi di Madrasah Aliyah Negeri 1 Bone.

\section{d. Evaluasi}

Evaluasi merupakan elemen terakhir dari proses manajemen. Meskipun menjadi elemen terakhir namun fungsi evaluasi sangatlah besar. Proses evaluasi yang dilakukan terhadap kegiatan-kegiatan yang telah dilaksanakan, memungkinkan seorang pemimpin mengetahui kelebihan dan kekurangan pelaksanaan kegiatan tersebut. Selain memperoleh kelemahan dan kelebihan, evaluasi juga berfungsi untuk mendapatkan pemecahan masalah bagi kegiatan-kegiatan yang akan dilakukan selanjutnya. ${ }^{9}$

Proses evaluasi kegiatan humas di Madrasah Aliyah Negeri 1 Bone dilaksanakan langsung oleh kepala madrasah beserta wakamad humas dan diikuti oleh panitia-panitia pelaksana yang telah dibentuk untuk pelaksanaan kegiatan humas. Kepala Madrasah mengungkapkan:

Dari setiap pelaksanaan kegiatan humas, pastinya tidak luput dari kekurangan meski banyak manfaat yang diperoleh madrasah. Beberapa kegiatan yang dilaksanakan, selalu kendala terberatnya ada pada pendanaan, karena tidak ada dana dari sekolah khusus dialokasikan untuk kegiatan humas. Berhubung kegiatan tersebut tidak memiliki dana, terpaksa panitianya berusaha sendiri. Mereka melakukan kegiatan-kegiatan yang bisa memasukkan dana seperti bazar, kegiatan pameran, dimana kegiatan tersebut melibatkan bantuan dari masyarakat luar dalam pengumpulan dana.

Hal senada juga diungkapkan oleh bapak Abd. Azis selaku wakil ketua komite sekolah:

Dalam pelaksanaan kegiatan kehumasan terkadang muncul kendala, seperti kepercayaan orang tua siswa berkurang terhadap sekolah. Hal tersebut berkaitan erat dengan pendanaan. Maka dari itu sekolah mengambil tindakan yang dapat membangun kepercayaan masyarakat khususnya orang tua siswa. Dalam mengelola bantuan dari masyarakat sekolah tidak lagi terlibat langsung namun diberikan wewenang kepada masyarakat dan pihak sekolah tidak lagi menentukan besaran sumbangan yang harus diberikan masyarakat khususnya orang tua siswa.

\footnotetext{
${ }^{9}$ Mutakallim, “Pengawasan, Evaluasi Dan Umpan Balik Stratejik,” Volume V, Nomor 2 (2016).
} 
Gambaran hasil penelitian tersebut memberikan masukan berupa pentingnya tahapan evaluasi dalam kegiatan-kegiatan kehumasan. Kelebihan dan kekurangan dari palaksanaan kegiatan kehumasan dapat dijadikan pelajaran untuk membangun partisipasi masyarakat yang lebih basar untuk membantu lembaga pendidikan membangun dan menjaga eksistensinya ditengah masyarakat. Apa yang diungkapkan oleh Kepala Madrasah dan Wakil Ketua Komite Sekolah Madrasah Aliyah Negeri 1 Bone menunjukkan bahwa betapa pentingnya posisi masyarakat yang mengambil perannya sebagai parnert dalam sebuah lembaga pendidikan untuk mendukung keberlangsungan setiap kegiatan-kegiatan yang dilakukan oleh sekolah.

\section{Peran Masyarakat di Madrasah Aliyah Negeri 1 Bone}

Salah satu kunci keberhasilan sekolah di luar prestasi-prestasi yang diraih adalah tingginya partisipasi masyarakat dalam mendukung penyelenggaraan pendidikan.Partisipasi masyarakat bisa dalam bentuk apapun, misalnya keterlibatan dalam kegiatan-kegiatan komite sekolah, serta pemberian bantuan materil dan moril. Normina mengungkapkan bahwa harus disadari keberadaan masyarakat dalam dunia pendidikan menjadi salah satu tolak ukur keberhasilan penyelenggaraan pendidikan. Kunci utama dalam hubungan ini adalah menumbuhkan rasa saling percaya atara masyarakat dengan sekolah. Bila sekolah mendapat kepercayaan dan dukungan dari masyarakat dapat dipastikan pendidikannya menjadi maju, sebaliknya jika tidak mendapat dukungan maka pendidikan di sekolah tersebut memprihatinkan. ${ }^{10}$

Ada beberapa bentuk partisipasi masyarakat dalam pendidikan, seperti bantuan finansial, bantuan material, bantuan akademik, bantuan kultural dan bantuan evaluatif. Bantuan finansial dapat berupa dana yang tidak ditetapkan besarannya, tergantung keinginan masyarakat. Bantuan tersebut biasanya diberikan untuk keperluan pengembangan pendidikan seperti beasiswa, pembangunan rumah ibadah, atau dukungan pendanaan kegiatan siswa. Bantuan material dapat berupa material bahan bangunan untuk perbaikan dan peningkatan sarana prasarana sekolah. Bantuan akademik berupa perhatian orang tua terhadap pendidikan anaknya yang bukan hanya disekolah tetapi juga dirumah. Selain itu bantuan akademik juga bisa dilakukan masyarakat dalam bentuk pemberian beasiswa bagi anak yang kurang mampu, dan penyediaan tempat magang untuk memperluas pengetahuan siswa di dunia praktif. Sementara bantuan kultural dapat berupa pemeliharaan nilai moral, pemberian contoh yang baik yang diberikan masyarakat kepada warga sekolah. Selanjutnya, bantuan evaluatif dapat berupa partisipasi masyarakat dalam mengontrol penyelenggaraan pendidikan. ${ }^{11}$

\footnotetext{
${ }^{10}$ Normina Normina, "PARTISIPASI MASYARAKAT DALAM PENDIDIKAN,” ITTIHAD (2016). ${ }^{11}$ Ibid.
} 
Adapun peran masyarakat di Madrasah Aliyah Negeri 1 Bone saat ini cukup baik. Masyarakat khususnya orang tua banyak berperang aktif melalui komite sekolah maupun kegiatan-kegiatan lain seperti ikut dalam kegiatan maulid, pemberian bantuan berupa dana dan material bangunan, maupun bantuan dari segi non materil. Salah satu bukti adanya partisipasi masyarakat berupa bangunan musholla yang merupakan bangunan hasil swadaya masyarakat sebagai bentuk dukungan terhadap pendidikan agama di Madrasah Aliyah Negeri 1 Bone. Bangunan tersebut sepenuhnya hasil kerjasama masyarakat, melalui bantuan dana, material, dan lainnya. Selain itu masyarakat juga aktif dalam mendukung pengembangan pendidikan melalui sisi dukungan akademik. Penyusunan visi misi maupun programprogram kerja lainnya tidak luput dari partisipasi masyarakat yang diundang oleh pihak sekolah untuk memberikan sumbangsih masukan untuk pengembangan sekolah ke depannya.

Keberhasilan Madrasah Aliyah Negeri 1 Bone dalam membangun partisipasi masyarakat untuk mendukung pengembangan sekolah memang tidak serta merta terjadi begitu saja. Hal tersebut diperoleh dari hasil kerja keras yang panjang, terutama kepemimpinan kepala madrasah dan dukungan dari berbagai pihak seperti pengelola humas madrasah, guru, tenaga kependidikan, komite sekolah, dan siswa. Semua berkolaborasi memajukan sekolah, menjaga nama baik sekolah, dan berkontribusi dalam bentuk materil dan moril. Kunci utama dalam membangun hubungan ini adalah keterbukaan dan menjaga kepercayaan antara pihak sekolah dan masyaratak.

\section{KESIMPULAN}

Berdasarkan hasil pembahasan yang telah dipaparkan sebelumnya, dapat disimpulkan bahwa:

1. Madrasah Aliyah Negeri 1 Bone memiliki organisasi humas yang dikelola oleh Wakamad bagian humas yang menjalankan fungsi manajemen humas untuk membangun partisipasi masyarakat dalam membantu penyelenggaraan pendidikan di Madrasah tersebut. Kegiatan-kegiatan humas yang dilaksanakan melalui prosedur manajemen humas yakni dimulai dengan tahapan perencanaan, pengorganisasian, pelaksanaan kerja, dan evaluasi. Semua tahapan manajemen humas tersubut sangatlah penting, namun yang paling penting adalah pada bagian evaluasi dimana Madasah Aliyah Negeri 1 Bone memperoleh informasi penting tentang kelebihan dan kekurangan kegiatan-kegiatan kehumasan yang telah dilaksanakan. Mengetahui hal tersebut, menjadikan Madrasah Aliyah Negeri 1 Bone memiliki pengetahuan tentang strategi apa yang bisa diterapkan selanjutnya dalam manajemen humas sehingga masyarakat dapat berpartisipasi aktif pada semua kagiatan kehumasan yang akan diselenggarakan.

2. Madrasah Aliyah Negeri 1 Bone membangun partisipasi masyarakat melalui pelibatan masyarakat pada setiap kegiatan-kegiatan kehumasan. Partisipasi masyarakat berupa bantuan materil dan moril 
sebagai upaya peningkatan pendidikan pada madrasah. Dalam membangun partisipasi masyarakat, yang menjadi kunci utama keberhasilan madrasah tersebut adalah keterbukaan pengelolaan madrasah serta membangun kepercayaan masyarakat kepada madrasah. Kedua hal tersebut sangat penting selain dari melibatkan masyarakat pada kegiatan. Ketiga hal itu membuat terciptanya rasa saling memiliki dari masyarakat untuk madrasah dan dari madrasah untuk masyarakat.

\section{DAFTAR RUJUKAN}

Manda. "FUNGSI PENGORGANISASIAN DAN EVALUASI PESERTA DIDIK." Kelola: Journal of Islamic Education Management 1, no. 1 (2016): 89-101.

Maskur, M. "Eksistensi Dan Esensi Pendidikan Madrasah Di Indonesia.” Terampil : Jurnal Pendidikan dan Pembelajaran Dasar (2017).

Mulyono, Mulyono. “TEKNIK MANAJEMEN HUMAS DALAM PENGEMBANGAN LEMBAGA PENDIDIKAN ISLAM.” ULUMUNA (2011).

Murni. "KONSEP MANAJEMEN HUMAS PADA LEMBAGA PENDIDIKAN ISLAM." Jurnal Intelektualita (2017).

Mutakallim. "Pengawasan, Evaluasi Dan Umpan Balik Stratejik." Volume V, Nomor 2 (2016).

Nadlir. "MANAJEMEN HUBUNGAN MASYARAKAT DALAM PENINGKATAN MUTU PENDIDIKAN DI MADRASAH TSANAWIYAH (MTs.) MA'ARIF NU 1 JATILAWANG BANYUMAS.” INSTITUT AGAMA ISLAM NEGERI PURWOKERTO, 2018.

Normina, Normina. "PARTISIPASI MASYARAKAT DALAM PENDIDIKAN.” ITTIHAD (2016).

Nurul Ahsin. "PANDANGAN MASYARAKAT PERKOTAAN DALAM MEMILIH LEMBAGA PENDIDIKAN ISLAM: Studi Tentang Parental Choice in Education Di SD Plus Rahmat Kota Kediri.” Didaktika Religia $\quad 3, \quad$ no. 12015 (2015). https://jurnal.iainkediri.ac.id/index.php/didaktika/article/view/153.

Qoimah, Qoimah. "MEMBANGUN PELAYANAN PUBLIK YANG PRIMA: STRATEGI MANAJEMEN HUMAS DALAM PENYAMPAIAN PROGRAM UNGGULAN DI LEMBAGA PENDIDIKAN." Islamic Management: Jurnal Manajemen Pendidikan Islam (2018).

Wati, Efni. “Manajemen Hubungan Sekolah Dan Masyarakat.” Jurnal Manajer Pendidikan (2015). 